\title{
Research on Social E-commerce Marketing Mode Against the Background of Traditional Retail Transformation
}

\author{
Yuqing Chen ${ }^{1, *}$ \\ ${ }^{1}$ Jinan University, Shenzhen, Guangdong 518000, China \\ *Corresponding author. Email: 694957564@qq.com
}

\begin{abstract}
In the context of the dilemma faced by traditional e-commerce, the combination of social and ecommerce has promoted the transformation of retail enterprises. Against the background that the current retail e-commerce development is in trouble and eager to transform to social e-commerce, this article analyzes the current social e-commerce marketing model, discusses the problems existing in the social e-commerce marketing process and proposes four countermeasures and suggestions for social ecommerce. This article has certain theoretical significance and application value to promote the successful transformation and development of traditional retail.
\end{abstract}

\section{Keywords: retail transformation, social e-commerce, online marketing, Internet, marketing model}

\section{INTRODUCTION}

From the end of the 20th century to the beginning of the 21 st century, the traditional retail industry experienced the first transformation to retail ecommerce. After 20 years of rapid development, it is now facing a new dilemma in which the growth rate gradually slows down and the number of customers and stickiness decline. In recent years, the development of e-commerce platforms has encountered traffic bottlenecks, and e-commerce platforms led by Taobao and JD.com have faced the problems of lack of traffic and high acquisition costs. On the contrary, social platforms such as MicroBlog and WeChat have demonstrated efficient customer acquisition and fission capabilities. Short video software such as Tik Tok and Kuaishou have ample traffic, low user acquisition costs and high stickiness, attracting many companies to join. Therefore, social e-commerce came into being. As the integration of social traffic and e-commerce transactions continues to deepen, the prosperity of the social ecology has directly changed the problem of the separation between traditional retail operations and sales. Retail enterprises can not only use social media to shorten the distance with consumers and improve communication effects, but also further shorten the link length from operations to sales and reduce communication costs. The listing of social e-commerce companies such as Pinduoduo and Yunji has pushed social e-commerce to the forefront.

According to the "2018 China Social E-commerce Industry Development Report" published by the
Internet Society of China, the social e-commerce market has reached 1.139778 trillion yuan in 2018, a year-on-year increase of $66.7 \%$ [1]. It can be seen that the current social e-commerce market contains great value. As an emerging business marketing model, social e-commerce is about to become a new economic growth point. However, there are still various development dilemmas in the social e-commerce marketing process at this stage. Therefore, this paper analyzes the current main marketing model of social ecommerce, explores the problems of retail enterprises in social e-commerce model and proposes countermeasures, hoping to promote the successful transformation of the retail industry and the healthy development of social e-commerce.

\section{THE CONCEPT AND CHARACTERISTICS OF SOCIAL E-COMMERCE}

Social e-commerce refers to the social functions through social networking platforms or e-commerce platforms, which applies socialized elements such as attention, sharing, discussion, communication and interaction to e-commerce purchase services, assisting the purchase and sale of goods through social interaction, user-generated content and other means.

The characteristics of social e-commerce: one is to achieve precision marketing. The social e-commerce platform can create multiple traffic portals, and each portal can correspond to a characteristic consumption scenario and match the corresponding consumer group to achieve precision marketing. Second, the stickiness and interaction of customers are strong. When 
merchants and customers are in commercial behavior, they are essentially opposite in interest and it is more difficult to establish a trust relationship during the consumption process. However, social e-commerce can use its social nature to enhance the trust of buyers and sellers. The third is people-centered. Traditional ecommerce is centered on "goods", and social ecommerce is centered on "people". It establishes the connection between people, then builds trust, and then conducts trade activities.

\section{ANALYSIS OF THE MARKETING MODEL OF SOCIAL E-COMMERCE}

\section{A. Social sharing e-commerce model - taking "Pinduoduo" as an example}

Social sharing e-commerce mainly affects promotion and communication. The famous American sociologist Homans pointed out in his social exchange theory [2]: Any interpersonal relationship is essentially to exchange relationships through sharing, and the essence of sharing is interest. Interest-driven fission is to guide fission by means of interest exchange. Pinduoduo is guided by preferential benefits such as "group booking" and "doing the bargaining for me" to allow consumers to actively participate in the social sharing process of the circle of friends. This model mainly uses the psychology of users to buy affordable goods and take advantage of others and uses group purchase concessions, head of the group free of charge and other methods to cause user fission, and most of the products sold are products with high demand and high performance cost ratio.

Pinduoduo mainly introduces traffic through WeChat applets. There are three reasons why Pinduoduo chose WeChat as its main platform. First, the scattered traffic of the mobile Internet will gather on WeChat to provide a continuous flow operation foundation for Pinduoduo. The Pinduoduo WeChat Mini Program was launched in May 2017. In July 2017, the DAU of Pinduoduo Mini Program exceeded one million. As of the end of 2017, the cumulative user visits of Pinduoduo Mini Program exceeded 100 million. Second, WeChat is China's largest Internet social platform, gathering the largest number of thirdtier and fourth-tier city users and rural users in the country. These users are precisely the important target users of Pinduoduo, and more effective and precise marketing can be carried out for the target users. Third, with the rise of $\mathrm{WeChat}$, consumer products are also showing a trend of demassification. Consumers are divided into scattered groups, and each group of consumers will correspond to different differentiated products. The Pinduoduo platform has established a traffic distribution mechanism based on big data and achieved a virtuous cycle of matching the most suitable resources to the most suitable users through targeted marketing [3].

\section{B. Social content e-commerce model - taking "Little Red Book" as an example}

Social content e-commerce mainly influences purchase decisions. Little Red Book is different from Pinduoduo and other platforms that rely on WeChat eco-drainage. Since the initial establishment of the online community, the core competitive advantage is public praise communication between users, that is, the direct and effective communication from consumer to consumer makes it more authentic. Little Red Book started with the decision-making process in the early stage of consumer transactions. At the beginning, it mainly focused on the beauty categories that are of interest to young women and high in gross profit. It invited a lot of KOL, celebrities, Internet celebrities and talented users trained by the platform itself to share high-quality original "Amway" content, form PGC (professional production content) and drive UGC (userproduced content) output to a benign community atmosphere.

After using community diversion to fully stimulate customer demand, Little Red Book added the important segment of "e-commerce", integrating social and shopping in one platform, forming a closed-loop ecological business model of shopping-sharing-reshopping. In the early stage of this model, users have a sense of trust and authority, accumulating a certain reputation of the product. And then, it attracted fans and users to receive information, stimulate purchase desire, clarify the purpose of purchase and finally realize the purchase behavior. [4]

\section{Social retail e-commerce model - taking "Yunji Micro-store" as an example}

Social retail e-commerce mainly affects supply and sales. Social retail e-commerce mainly provides customers with one-stop pre-sales and after-sales services through intelligent analysis of data. Yunji Micro-store can be taken as an example, which concept is "saving money through own use, making money through sharing". Traditional B2C e-commerce provides a shop opening platform for shop owners at the back end. Merchants purchase their own goods, publicize on the platform and independently complete logistics and after-sales customer service. The feature of Yunji Micro-store is the personal retail solution. The platform provides shop owners with all services such as customer service, logistics, warehousing, finance, training, product promotion, etc., which greatly facilitates the operation of platform users (store owners) and realizes a guaranteed one-stop service for consumers. [5] In addition, Yunji Micro-store got rid of the traditional WeChat business distribution model. All 
users are managed by the platform. The platform designs promotional programs for users. Official subsidy promotion once a month and weekly brand activities will be arranged to maximize the interests of consumers and store owners.

\section{THE MAIN PROBLEMS OF SOCIAL E- COMMERCE MARKETING}

\section{A. Lack of supervision mechanism}

Social e-commerce is in the development stage. At present, there is still a lot of controversy in the social ecommerce industry standards. It lacks a unified set of standards to regulate the development of social ecommerce. Professor Huang Yiping, director of the Peking University Digital Finance Research Center and deputy dean of the National Development Research Institute, expressed the opinion that, "In the absence of supervision, if social e-commerce doesn't grasp the boundaries, it is easy to cause a loss of both sides". Social e-commerce has widely adopted a "fission" business model, and its boundary with pyramid selling is not yet clear. Social e-commerce platforms such as Yunji Micro-store and Peanut Diary have been punished by the industry and commerce department for involving pyramid selling. This will greatly limit the healthy development of social e-commerce. Therefore, the risk control capabilities and the upgrading ways of industrial models of social e-commerce companies are particularly important in the development process.

\section{B. Insufficient traffic stamina}

Traffic is the foundation for e-commerce platforms to survive, especially for mobile social e-commerce. Compared with traditional e-commerce, the main sources of traffic for social e-commerce are social media and public praise communication. The traffic is obtained through forwarding and sharing among users. Although the cost is low, the form is single. The amount of traffic depends on the size of the users' social network. Once the resources of acquaintances around users are developed, it is easy for the bottleneck of drainage to occur in the middle and late stages, and it is difficult to expand new users. In addition, with the continuous development of social e-commerce, more and more participants will quickly exhaust the traffic dividend of the social platform, and the marginal effect of user growth brought by the investment of social traffic will gradually decrease. [6]

\section{User trust crisis}

Social e-commerce is a product of the era of sharing economy. The core of the "sharing economy" can flourish lies in how the supply and demand sides build trust. [7] The development of social e-commerce relies on a "acquaintance + trust" model. The premise of this model's rapid development is a perfect credit system. However, at this stage, China's credit system is still not perfect and lack of authoritative personal credit system certification. The problem of user authentication of social platforms is difficult to solve, making it difficult for the socialized e-commerce trust economy to form, and it is also difficult to increase user loyalty and repurchase rate. In the early days, due to rapid expansion and low thresholds, merchants on social ecommerce platforms inevitably had problems like poor product quality, selling fakes and poor service attitudes. If a dispute arises, consumers can't provide shopping vouchers, transaction information and the seller's true information, resulting in consumers' inability to obtain after-sales protection and difficulties in defending their rights. When such a credit crisis occurs, users will consciously avoid such publicity and marketing, which is extremely unfavorable to the sustainable and good development of social e-commerce. Therefore, how to establish a perfect credit system and ensure a strong supervision are the problems that social e-commerce needs to solve urgently.

\section{COUNTERMEASURES AND SUGGESTIONS FOR SOCIAL E-COMMERCE MARKETING}

\section{A. Improving the supervision mechanism and supporting innovation and development}

The government should introduce relevant policies and regulations to regulate social e-commerce transaction behaviors, raise the entry threshold for social e-commerce and gradually establish a mature supervision mechanism similar to the traditional ecommerce platform on the social e-commerce platform, including a complaint reporting mechanism and a consumer rights protection mechanism. Perfect market regulations can also build consumer confidence, and government support can also promote the enthusiasm of companies to participate in social e-commerce. Therefore, government departments should increase the training of e-commerce talents, vigorously promote the "mass entrepreneurship and innovation" policy and promote the standardized and innovative development of socialized e-commerce. [8]

\section{B. Mining user needs and achieving precision marketing}

It is impossible for all enterprises to use only one product or marketing model to meet the needs of all consumers. When the social identity information of the brand supporters exposed by the social network platform is consistent with the potential consumer's social identity, consumers have a stronger willingness to buy [9]. Enterprises need to pay attention to the social identities of consumers and try to ensure the consistency of the social identities of existing supporters of the brand and target customers. At the 
same time, social e-commerce is different from traditional e-commerce. It focuses on "people". Therefore, social e-commerce must pay attention to the needs of users, do a good job in market segmentation, identify group characteristics with similar consumption habits and present customized marketing information output on the user side so as to hit users' pain points and improve customer loyalty.

\section{Promoting the transformation of supply chain digitization and customization}

For the traditional retail industry, in addition to focusing on its own transformation in the Internet environment, supply chain transformation constitutes an important part of its transformation. In recent years, the development of big data, cloud computing, artificial intelligence and other emerging information technologies has promoted the development of enterprise supply chains to a new stage of smart supply chains. The enterprise supply chain has begun to deeply integrate with the Internet and the Internet of Things. The level of digitalization and intelligence has been continuously improved, which has greatly enriched the scene of procurement management technology scenarios and promoted the transformation of new technology management methods such as traditional offline procurement to online procurement and smart procurement [10]. At the same time, the concept of supply chain management begins to be rapidly promoted, and the competition between enterprises begins to change from a single cost competition and quality competition to the "creating value for customers" competition. In order to respond to the characteristics of personalization, rapid change and discontinuity of social e-commerce consumer needs, social e-commerce enterprises should realize the expansion from general material procurement and product procurement for partners to professional, customized products and production materials and enterprise service procurement for consumers. [11]

\section{Deep integration of online and offline to realize new retail transformation}

The "ceiling" of the traditional e-commerce development has been vaguely visible, and retail ecommerce transformation is a unstoppable trend. Enterprises should gradually form a new deep integration retail model of "online + offline + logistics". Traditional retail brands have a mature offline marketing system, allowing audiences to experience the details and texture of products, experience product behavior, and allow companies to fully communicate with customers and understand the true psychology and needs of consumers. Online e-commerce is an extension of offline entities. Retail companies should actively use online platforms such as social media platforms, ecommerce platforms, and videos to carry out brand marketing communications, so that brand and product information can be quickly transmitted to brand fans and potential consumers, which may enable them to consume online. It is also necessary to develop social ecommerce to enable traditional retail brands to break through online and offline marketing barriers, realize online and offline traffic interconnection and online marketing to drive offline sales, thereby completing the efficient connection of goods and users and the closed loop of consumer services.

\section{CONCLUSION}

With the rapid development of social economy and science and technology and with the popularity of the Internet and the development of the network economy, the two major modules of "social contact" and "ecommerce" are gradually integrated. Social ecommerce has undoubtedly become a new hotspot in the e-commerce industry. This paper starts with the analysis of the three major operating modes of social ecommerce and reveals their applications in promotion and communication, purchase decision-making, and supply and sales. Through an in-depth study of the problems in the external supervision, internal drainage and user maintenance of traditional retail enterprises during its transition to social e-commerce, this paper comes up with 4 solutions, which have theoretical guiding significance for the traditional retail enterprises to successfully realize the transformation of social ecommerce in the Internet process. The future research direction of this research is to empirically demonstrate the theoretical framework of the social e-commerce operation model proposed in this paper, so as to further promote the transformation of traditional retail enterprises.

\section{References}

[1] Dong Baoming, Meng Pingli, Zhou Lulu. Research on the Retail Enterprise Marketing Model Against the Background of Social E-commerce [J]. Business Economics Research, 2020 (06). (in Chinese)

[2] Tan Guzheng. The Social Exchange Theory of Homans and Blau [J]. Social Sciences, 1986 (10): 55-59. (in Chinese)

[3] Zheng Gang, Lin Wenfeng. Pinduoduo: Quick Counterattack in the E-commerce Red Sea [J]. Tsinghua University Management Review, 2018 (09): 105-112. (in Chinese)

[4] Zang Menglu. Little Red Book: Left-handed Social Contact and Right-handed E-commerce [J]. Guangcai, 2018 (07): 34-36. (in Chinese)

[5] Xiao Shanglue. Yunji Micro-store: Creating a New Platform for Social Retailing [J]. Agricultural Economics, 2018 (03): 32-35. (in Chinese)

[6] Wang Jiexiang, Chen Weiru. Platform Evolution and Ecological Participant Strategy [J]. Tsinghua Management Review, 2019 (12): 76-85. (in Chinese)

[7] Li Liwei, He Qin. How to Talk About Sharing Without Trust? - Review on the Research of Trust in the Sharing Economy 
[J]. Foreign Economy and Management, 2018 (06): 141-152. (in Chinese)

[8] Han Guolan. Discussion on the Development of Socialized Ecommerce Against the Background of Sharing Economy [J]. Business Economics Research, 2018 (01): 71-73. (in Chinese)

[9] Hong Ruiyang, Wu Shuilong, Yuan Yongna, Jiang Lianxiong. Research on the Influence of Social Identity Information Consistency on Consumers' Purchase Intention - Based on the Public Praise Situation of Social Network Brand Supporters [J]. Journal of Marketing Science, 2017 (04): 67-82. (in Chinese)

[10] Shen Xiaojing, Liu Ruoyang, Jiang Xu. The Development History, Stage Characteristics and Future Prospects of Purchasing Management in the 70 Years of New China [J]. Management World, 2019 (10): 39-49. (in Chinese)

[11] Xiao Jinghua, Xie Kang, Wu Yao, Liao Xuehua. The Supply Chain Transformation from Partner-oriented to Consumeroriented - Double-case Study of E-commerce Enterprise Supply Chain [J]. Management World, 2015 (04): 137-154. (in Chinese) 